Tropical Journal of Pharmaceutical Research, February 2010; 9 (1): 45-50

(C) Pharmacotherapy Group,

Faculty of Pharmacy, University of Benin,

Benin City, 300001 Nigeria.

All rights reserved.

Research Article

Available online at http://www.tjpr.org

\title{
Stability-Indicating Reverse Phase HPLC Method for the Determination of Cefazolin
}

\author{
N Lalitha*, Pai PN Sanjay, MG Vyshak and Uvesh Kadri
}

Al-Ameen College of Pharmacy, Near Lalbagh Main Gate, Bangalore-560027, India

\begin{abstract}
Purpose: The aim of the present study was to establish the inherent stability of cefazolin through stress studies under a variety of $\mathrm{ICH}$ recommended test conditions and, also to develop a stability indicating assay.

Methods: A stability-indicating HPLC assay method was developed and validated for cefazolin using an isocratic RP-HPLC method which employed an SS Wakosil II- $C_{18}$ column (250 mm $\times 4.6 \mathrm{~mm}$ i.d., $\left.5 \mu \mathrm{m}\right)$ with a mobile phase consisting of phosphate buffer ( $p H$ 6.8) and methanol (5:2 v/v), and UV detection at $254 \mathrm{~nm}$ at a flow rate of $1 \mathrm{ml} / \mathrm{min}$. The stress testing of cefazolin was carried out under acidic, alkaline, neutral, oxidation and thermal conditions.

Results: The drug peak was well resolved from the peaks of the degradation products. The proposed method was validated for sensitivity, selectivity, linearity, accuracy, precision and solution stability. From the degradation studies it was found that the drug was thermally stable but unstable in acidic, alkaline, neutral and oxidative conditions. The response of drug was linear in the concentration Range of 1 - 50 $\mu \mathrm{g} / \mathrm{ml}$ with the number of theoretical plates, and tailing factor being 1341 and 1, respectively. Limit of detection and limit of quantification were 0.1 and $0.2, \mu \mathrm{g} / \mathrm{ml}$ respectively while recovery ranged from 95 $100 \%$. Method precision and precision of the system were within the limits of acceptance criteria.

Conclusion: This study presents a simple and validated stability-indicating HPLC method for the estimation of cefazolin in the presence of degradation products. The developed method is specific, accurate, precise and robust. All the degradation products formed during forced degradation studies were well separated from the analyte peak.
\end{abstract}

Keywords: Cefazolin; Stability-indicating assay; Reversed-phase HPLC 


\section{INTRODUCTION}

Stability is defined as the capacity of a drug substance or drug product to remain within established specifications to maintain its identity, strength, quality, and purity throughout the re-test or expiration dating periods [1]. Stability testing of an active substance or finished product provides evidence on how the quality of a drug substance or drug product varies with time. It is influenced by a variety of environmental factors such as temperature, humidity and light. Knowledge from stability studies enables understanding of the long-term effects of the environment on drugs. Stability testing provides information about degradation mechanisms, potential degradation products, possible degradation pathways of the drug as well as interaction between the drug and excipients in the drug product. The results are applied in developing manufacturing processes and selecting proper packaging, storage conditions, product's shelf life and expiration dates [2-4]. Because the distribution environment is highly variable, products must be distributed in a manner that ensures product quality will not be adversely affected. The effect of possible temperature and humidity fluctuations, outside of labelled storage conditions, during transportation of drug products can be evaluated on the basis of the stability analysis of the drug $[4,5]$.

Determination of cefazolin by various methods has been described but the stability of cefazolin has only been evaluated with electrophoresis [6], calorimetry [7] and gamma radiations [8]. A number of high performance liquid chromatographic (HPLC) methods have been developed for the cephalosporins in plasma [9-13] but only a few stability-indicating HPLC methods for drug analysis has been reported [14,15]. The aim of the present study was to establish the inherent stability of cefazolin through stress studies under a variety of $\mathrm{ICH}$-recommended tests conditions [2] and to develop a stability-indicating assay for the drug [16].

Cefazolin sodium [17] is $(6 \mathrm{R}, 7 \mathrm{R})-3-(((5-$ Methyl-1, 3,4-thiadiazol-2-yl) thio -methyl)-8oxo-7-2-(1H-tetrazol-1-yl) acetamido)-5-thia1-azabicyclo (4.2.0) oct-2-ene-2-carboxylate with molecular formula $\mathrm{C}_{14} \mathrm{H}_{14} \mathrm{~N}_{8} \mathrm{O}_{4} \mathrm{~S}_{3}$. It is a first generation cephalosporin and it inhibits cell wall biosynthesis. Cephalosporins are bactericidal and have the same mode of action as other beta-lactam antibiotics (such as the penicillins). Modified cephalosporins have a much wider activity than the penicillins, and also show less toxicity and better stability [18].

\section{EXPERIMENTAL}

\section{Materials}

Pure cefazolin was received as a gift from Karnataka Antibiotics Pharmaceuticals Ltd, Bangalore, India. Cefazolin injection (Azolin Injection, 500mg, Biochem-Pharmaceutical Industries, Mumbai, India) was purchased from local drug market. HPLC grade methanol was purchased from Qualigens Fine Chemicals, Mumbai, India. Millipore water was obtained with Millipak $0.22 \mu \mathrm{m}$ filter. Buffer materials and all other chemicals were of analytical-reagent grade.

\section{Instrumentation and chromatographic conditions}

The HPLC system consisted of model 10AT Shimadzu- SPD10A detector an SS Wakosil II- $\mathrm{C}_{18}$ column $(250 \mathrm{~mm} \times 4.6 \mathrm{~mm}$ i.d., $5 \mu \mathrm{m})$. Separation was carried out by isocratic elution with a mixture of phosphate buffer $(\mathrm{pH}$ 6.8) and methanol in the ratio of $5: 2(\mathrm{v} / \mathrm{v})$ at a flow rate of $1 \mathrm{ml} / \mathrm{min}$. The detector was monitored at $254 \mathrm{~nm}$ and the injection volume was $100 \mu \mathrm{l}$. 
Preparation of standard and sample solutions

Standard preparation: A standard stock solution of $1 \mathrm{mg} / \mathrm{ml}$ of cefazolin in the mobile phase was prepared in a $10 \mathrm{ml}$ volumetric flask. Working standard solutions were prepared by diluting the stock solution with the mobile phase to obtain cefazolin concentrations ranging from $0.1-100 \mu \mathrm{g} / \mathrm{ml}$.

Sample preparation: Cefazolin sodium injection of $500 \mathrm{mg}$ was dissolved in $2 \mathrm{ml}$ water for injection and from this solution, a working sample solution of $2 \mu \mathrm{g} / \mathrm{ml}$ was prepared with the mobile phase in a $10 \mathrm{ml}$ volumetric flask and filtered through a 0.22 $\mu \mathrm{m}$ nylon syringe filter.

\section{Degradation studies}

Standard cefazolin with a concentration of $1 \mathrm{mg} / \mathrm{ml}$ was used in all the degradation studies. Standard cefazolin solutions were subjected to stress conditions in $0.1 \mathrm{~N} \mathrm{HCl}$ and $0.1 \mathrm{~N} \mathrm{NaOH}$ at of temperature of $80^{\circ} \mathrm{C}$ at time intervals. After completion of the degradation processes, the solutions were neutralized and diluted with mobile phase. For neutral studies, standard cefazolin of $1 \mathrm{mg} / \mathrm{ml}$ was dissolved in water and subjected to stress conditions at a temperature of $80{ }^{\circ} \mathrm{C}$ at time intervals. For the oxidative studies, the standard cefazolin solution was subjected to stress conditions in 3 and $30 \%$ hydrogen peroxide at room temperature for $30 \mathrm{~min}$. After the solutions had been subjected to the various stress conditions, $0.1 \mathrm{ml}$ of the degraded solutions were withdrawn at the various intervals and subjected and analysed after suitable dilution to $10 \mu \mathrm{g} / \mathrm{ml}$ with mobile phase. The chromatographic analysis of the degraded solutions (100 $\mu \mathrm{l}$ each) were carried out under the same chromatographic conditions.

\section{Method validation}

Analytical method validation was carried out as per ICH method validation guidelines [16].
The validation parameters addressed were specificity, precision (inter-day and intra-day), linearity, accuracy, limit of detection, limit of quantitation, robustness and stability of cefazolin in mobile phase. A standard plot was constructed for cefazolin in the range of $0.1-50 \mu \mathrm{g} / \mathrm{ml}$. Accuracy was determined by fortifying the mixture of pre-analysed standard of three known concentrations of the drugs with the marketed sample.

\section{RESULTS}

\section{Development and optimization of the stability-indicating HPLC method}

An isocratic method was found suitable to optimise the separation of major degradation products formed under various stress conditions. The best resolution was achieved with an initial run of a mixture of phosphate buffer ( $\mathrm{pH} \mathrm{6.8)} \mathrm{and} \mathrm{methanol} \mathrm{in}$ the ratio of $5: 2(\mathrm{v} / \mathrm{v})$ at a flow rate of 1 $\mathrm{ml} / \mathrm{min}$; the retention time was observed to be $5.72 \mathrm{~min}$.

\section{Degradation behavior}

HPLC data on samples (powder and solution combination) obtained on stress testing (alkaline, acidic, neutral, thermal and oxidative conditions) are indicated in Table 1.

\section{Acidic conditions}

The standard drug cefazolin at $80{ }^{\circ} \mathrm{C}$ in $0.1 \mathrm{M} \mathrm{HCl}$ was degraded in $5 \mathrm{~min}$. Within 10 min $87.5 \%$ drug was degraded. The chromatogram showed major degradation products at retention times (RT) of $2.96 \mathrm{~min}$ and 3.93 min with the standard peak at 5.9 $\min$.

\section{Alkali conditions}

The drug was highly degraded in $0.1 \mathrm{M}$ $\mathrm{NaOH}$ at $80{ }^{\circ} \mathrm{C}$, being degraded within 10 min. Three major degradation peaks at RT of $2.00,2.26$, and 2.96 min were observed while 
Table 1: Degradation data for cefazolin

\begin{tabular}{ccccc}
\hline Stress condition & $\begin{array}{c}\text { Degradation } \\
\text { time }(\mathbf{m i n})\end{array}$ & $\begin{array}{c}\text { Area of } \\
\text { peak }^{*}\end{array}$ & $\begin{array}{c}\text { Degradation } \\
(\%)\end{array}$ & $\begin{array}{c}\text { Active drug present } \\
\text { after degradation (\%) }\end{array}$ \\
\hline Standard drug & - & 1683293 & - & - \\
Acidic & 10 & 108335 & 87.53 & 12.46 \\
Alkaline & 10 & 412316 & 61.88 & 38.10 \\
Neutral & 30 & 1088441 & 17.01 & 82.98 \\
Neutral & 60 & 746143 & 33.29 & 66.11 \\
Oxidative $\left(3 \% \mathrm{H}_{2} \mathrm{O}_{2}\right)$ & 20 & 1712823 & 70.33 & 29.88 \\
Oxidative $\left(30 \% \mathrm{H}_{2} \mathrm{O}_{2}\right)$ & $30 \mathrm{~min}$ & 393803 & 95.6 & 5.36 \\
Thermal & $36 \mathrm{hr}$ & 1180032 & 29.89 & 70.10 \\
\hline
\end{tabular}

${ }^{*}$ Mean of three measurements

Table 2: Recovery data for cefazolin $(n=3)$

\begin{tabular}{ccccccc}
\hline $\begin{array}{c}\text { Standard } \\
\text { cefazolin } \\
(\mu \mathbf{g} / \mathbf{m l})\end{array}$ & $\begin{array}{c}\text { Test } \\
\text { cefazolin }(\mu \\
\mathbf{g} / \mathbf{m l})\end{array}$ & $\begin{array}{c}\text { Total } \\
\text { conc. } \\
(\mu \mathbf{g} / \mathbf{m l})\end{array}$ & $\begin{array}{c}\text { Peak } \\
\text { area }^{*}\end{array}$ & $\begin{array}{c}\text { Analysed total } \\
\text { amount }(\mu \mathbf{g} / \mathbf{m l})\end{array}$ & $\begin{array}{c}\text { Recovery of } \\
\text { standard } \\
(\mu \mathbf{g} / \mathbf{m l})\end{array}$ & $\begin{array}{c}\text { Recovery of } \\
\text { standard (\%) }\end{array}$ \\
\hline 2 & 2 & 4 & 534115 & 3.9 & 1.9 & 95 \\
4 & 2 & 6 & 761349 & 5.8 & 3.8 & 95 \\
6 & 2 & 8 & 1102675 & 8 & 6 & 100 \\
\hline
\end{tabular}

\section{Neutral conditions}

The degradation of standard cefazolin solution was highly labile in neutral medium (water) at room temperature $\left(27 \pm 2{ }^{\circ} \mathrm{C}\right)$ with $33.3 \%$ of the drug decomposed in $60 \mathrm{~min}$. The major degradation product appeared at RT of $2.50 \mathrm{~min}$ and the standard peak at $5.97 \mathrm{~min}$.

\section{Oxidative degradation}

The degradation of cefazolin in $3 \%$ hydrogen peroxide (oxidative conditions) at different time interval of 20 min was $29.9 \%$, giving rise to one degraded peak at RT of 2 min with the hydrogen peroxide and standard peaks occurring at RT of 2.98 and $5.90 \mathrm{~min}$, respectively. In $30 \%$ hydrogen peroxide, $95.6 \%$ drug was degraded in 10 min with the degradation peak occurring at RT of 1.97 min. Hydrogen peroxide and standard peaks occurred at 3.01 and 5.95 min, respectively. After $20 \mathrm{~min}$, the drug was completely degraded.

\section{Thermal degradation}

Under thermal degradation conditions, standard cefazolin solution was stable for 24 h. exposition at $50{ }^{\circ} \mathrm{C}$. After $48 \mathrm{~h}$ of thermal stress, $29.89 \%$ of cefazolin was degraded, while $70.10 \%$ (did not any degraded peaks) was recovered.

\section{Validation of method}

\section{System suitability}

The retention time of cefazolin was $5.67 \mathrm{~min}$. Efficiency and tailing factor at $5 \%$ of the height of the main peak were determined, giving $N=1341.12$, and tailing factor $=1$.

Trop J Pharm Res, February 2010; 9 (1): 48 


\section{Linearity}

Ten-point calibration curves were obtained in a concentration range of 1 to $50 \mu \mathrm{g} / \mathrm{ml}$ for cefazolin based on three independent determinations performed at each concentration. The response for the drug was linear and the calibration equation was $y=$ $291171 x-26955$ with $R^{2}=0.9989$.

Limit of detection (LOD) and limit of quantitation (LOQ) for cefazolin

The limit of detection and limit of quantitation for cefazolin were 0.1 and $0.3 \mu \mathrm{g} / \mathrm{ml}$, respectively.

\section{Accuracy}

Recovery ranged from $95-100 \%$. The recovery study data are given in Table 2 .

\section{Precision}

Method precision and precision of the system were within the limits of acceptance criteria. Assessment of the system precision showed that the relative standard deviation was 0.8033 and $0.5856 \%$ for 4 and 2 mcg, respectively. The data for inter- and intra-day precision are given in Table 3.

\section{Ruggedness}

The ruggedness of the developed method was established by determining cefazolin in the same chromatographic system and the same column by two analysts on different days. The assay result indicated that the method had a high precision. Additionally, good separation, effective separation of the drug from its degraded product was always achieved which suggests that the method was selective for all the components tested.

\section{Solution stability}

The stability of cefazolin solution was established by keeping the solution at room temperature for $24 \mathrm{~h}$. The result showed no significant change in concentration, thus confirming the stability of the drug in the solvent used for the analysis.

\section{DISCUSSION}

In this study, the inherent stability of cefazolin was established based on tests utilising $\mathrm{ICH}$ recommended stress conditions. The drug degraded extensively in alkaline, acidic, neutral and oxidative conditions. Mild degradation was seen in thermal conditions without any degraded products. Drug peak was well resolved from the peak of its degradation product as well as those of the excipients in cefazolin sodium injection formulation. The developed method was simple, accurate, precise, specific, selective and rugged and, therefore, it should be suitable for the analysis of cefazolin and its degraded products of the drug product in the industry.

Table 3: Inter and intra-day precision

\begin{tabular}{ccccc}
\hline & \multicolumn{2}{c}{$\begin{array}{c}\text { Inter-day measured } \\
\text { conc. }(\boldsymbol{\mu g} / \mathbf{m l})\end{array}$} & \multicolumn{2}{c}{$\begin{array}{c}\text { Intra-day measured } \\
\text { conc. }(\boldsymbol{\mu g} / \mathbf{m l})\end{array}$} \\
\cline { 2 - 5 } Actual & \multicolumn{2}{c}{$\mathbf{R S D}(\%, \mathbf{n = 3})$} & $\boldsymbol{\mu g} / \mathbf{m l})$ & $\mathbf{R S D}(\%, \mathbf{n}=\mathbf{3})$ \\
\cline { 2 - 5 } conc. $(\boldsymbol{\mu g} / \mathbf{m l})$ & $\boldsymbol{\mu} / \mathbf{m l})$ & 1.8153 & 0.9 & 0.6509 \\
1 & 0.9 & 1.9191 & 2.0 & 0.9329 \\
2 & 2.0 & 1.7236 & 3.9 & 1.3516 \\
4 & 3.9 & 0.5500 & 5.6 & 1.2570 \\
6 & 5.7 & 1.6507 & 8.2 & 1.9843 \\
8 & 7.7 & 0.6146 & 10.1 & 1.0525 \\
10 & 10.2 & & & \\
\hline
\end{tabular}




\section{CONCLUSION}

This study presents a simple and validated stability-indicating HPLC method for the estimation of cefazolin in the presence of its degradation products. The developed method is specific, accurate, precise and robust. All the peaks of the degradation products formed during forced decomposition studies were well separated from the analyte peak. This demonstrates that the developed method was specific and stability-indicating. The method was successfully applied to the analysis of a commercial cefazolin injection formulation, as no interference due to excipients or other components present was observed.

\section{ACKNOWLEDGEMENT}

The authors are grateful to Karnataka Antibiotics and Pharmaceuticals Ltd, Bangalore, India, for providing some materials free of charge, and to all our research colleagues at the firm's Department of Quality Assurance for their support

\section{REFERENCES}

1. FDA Guidance for Industry. Stability Testing of Drug Substances and Drug Products (Draft Guidance), Food and Drug Administration, Rockville, MD, USA, 1998.

2. $\mathrm{ICH}$ Good Manufacturing Practice for Active Pharmaceutical Ingredients. International Conference on Harmonisation, IFPMA, Geneva, 2000.

3. Carstensen JT, Rhodes CT. A rational approach to stability testing and analytical development for NCE, drug products marketed product stability testingIn: In: Drug Stability: Principles and Practices, Wolfgang G, Ed, New York, Marcel Dekker, 2000; pp 415-81.

4. Emmanuel $O A$. Pharmaceutical Manufacturing Handbook. In: Effect of Packaging on Stability of Drugs and Drug Products, Shayne $C D$, Shayne CG, Eds,, John Wiley \& Sons, Inc, New Jersey, 2008; pp 641-686..
5. ICH Harmonized Tripartite Guideline, Q1F: Stability Data Package For Registration Applications in Climatic Zones III and IV, EMEA, London, 2003.

6. Beverly N, Brenda C, Stephen S. The use of capillary electrophoresis to monitor the stability of a dual-action cephalosporin in solution. J. Pharm. Biomed. Anal. 1995; 14: 73-83.

7. Pikal MJ, Dellerman KM. Stability testing of pharmaceuticals. Int. J. Pharm. 1989; 50: 233252.

8. Jacobs GP. Stability of cefazolin and other new cephalosporins following gamma irradiation. Int. J. Pharm. 1983; 17: 29-38.

9. Sosnowska NS, Ociosa A, Fuks L. Selectivity of similar compounds identification using IR spectrometry: $\beta$-Lactam antibiotics. J. Molec Str. 2006; 792-793: 110-114.

10. Al-Rawithi S, Hussein R, Raines DA, Al-Showaier I, Kurdi $W$. Sensitive assay for the determination of cefazolin or ceftriaxone in plasma utilizing LC. J. Pharm. Biomed. Anal, 2000; 22(2): 281286.

11. Sorensen $L K$, Snor $L K$. Determination of cephalosporins in raw bovine milk by highperformance liquid chromatography. J. Chromatogr A, 2000; 882(1-2): 145-151.

12. Signs $S A$, File TM, Tan JS. High-pressure liquid chromatographic method for analysis of cephalosporins. Antimicrob. Agents Chemother, 1984; 26: 652-655.

13. Joshi S. HPLC separation of antibiotics present in formulated and unformulated samples. J. Pharm. Biomed. Anal. 2002; 28: 795-809.

14. $X u Q A$, Trissel $L A$. Stability-Indicating HPLC Methods for Drug Analysis, American Pharmacists Association, USA and the Pharmaceutical Press, UK, 2008.

15. Bakshi $M$, Singh $B$, Singh $A$, Singh $S$. The $I C H$ guidance in practice: Stress degradation studies on ornidazole and development of a validated stability-indicating assay. J. Pharm. Biomed. Anal. 2001; 26(5-6): 891-897.

16. Steven W. BioPharm International - Analytical Methods: A Statistical Perspective on the ICH Q2A and Q2B Guidelines for Validation of Analytical Methods, Rockville, MD 20850, 2006. http://www.statisticaloutsourcingservices .com/Methval.pdf. Accessed 2 December 2008.

17. USP 27/NF-22. The United States Phamacopoeial Convection Inc. Rockville, MD, 2004, p 328.

18. Deshpande $A D$, Baheti KG, Chatterjee NR. Degradation of b-lactam antibiotics. Current Sci. 2004; 87: 1684-1695. 